\title{
BARCELONA(S) \\ CIDADE DOS PROJECTOS OU PROJECTOS DA CIDADE?
}

MARGARIDA QUEIRÓS ${ }^{1}$

\begin{abstract}
Resumo - A imagem internacional de Barcelona associou-se à existência de um modelo urbano inovador, conhecido por "modelo Barcelona", iniciado nos anos 1980. O modelo a que nos referimos não retrata apenas assuntos essenciais ao planeamento urbano, como as políticas públicas ou as novas estratégias económicas, mas também se refere à cultura urbana, inclusão social e participação cidadã. Ao longo do tempo este modelo "evoluiu" e tem sido alvo de longos debates e de activa controvérsia. Barcelona(s) retoma o modelo e discute alguns dos aspectos em que este é recorrentemente elogiado e colocado em causa. O propósito é estimular a reflexão sobre um desafio: como encontrar a proporção certa entre as estratégias públicas e privadas de planeamento urbano de longo prazo e os projectos imediatos, a liderança dos poderes públicos e os consensos sociais? Os autores dos artigos incluídos neste número - que este texto apresenta -, têm dedicado uma parte importante da sua investigação aos processos políticos, económicos e sociais que fazem evoluir esta cidade e a sua área metropolitana. Remetem para situações complexas (a diversas escalas) despoletadas pelo modelo e debatem as suas consequências.
\end{abstract}

Palavras-chave: Barcelona, modelo Barcelona, planeamento estratégico, governança.

\begin{abstract}
Barcelona(s). A CITY of MANy Projects, OR PROJeCts For the CITY? The international image of Barcelona has come to be associated with an innovative urban model known as the "Barcelona model", which dates back to the 1980s. This model is not limited to such central aspects of urban planning as public policies and new economic strategies. Instead, some of its key features are concerned with social inclusion, urban culture and citizen participation. However, the model itself has evolved over time and has been the object of heated debates and controversy. The aim of the article is to discuss this model and some of the main praises and criticisms it raised. This is done with a view to contributing to the debate around the following challenge: how are we to achieve an adequate balance between short-term projects and long-term public and private urban planning strategies, as well as between public
\end{abstract}

Recebido: 16/04/2010. Aceite: 19/10/2010.

1 Professora Auxiliar do Instituto de Geografia e Ordenamento do Território e Investigadora do Centro de Estudos Geográficos, da Universidade de Lisboa. E-mail: margaridav@campus.ul.pt 
leadership and social consensus? The authors of the articles included in this issue of Finisterra - for which this article also serves as an introduction - have undertaken substantial research on the political, economic and social processes that drive this city and its metropolitan area. They highlight some of the complex situations that arise at various scales within the context of this model and they discuss their various consequences.

Keywords: Barcelona, Barcelona model, strategic planning, governance.

Résumé - Barcelone(s). Ville de projets ou projets de la Ville? L'image internationale de Barcelone est aujourd'hui liée à l'existence d'un modèle urbain innovant, le «modèle Barcelone», élaboré lors des années 80 . Celui-ci ne traite pas seulement des sujets essentiels de la planification urbaine, comme les politiques publiques ou les nouvelles stratégies économiques, mais il se réfère aussi à la culture urbaine, à l'inclusion sociale et à la participation citoyenne. Ce modèle a évolué et a été l'objet de longs débats et d'une active controverse. Barcelone (s) reprend ce modèle et discute certains des aspects qui ont été loués ou mis en cause de façon répétée. Ceci, afin de stimuler la réflexion sur ce défi: comment trouver un bon équilibre entre stratégies publiques et privées, entre planification urbaine durable et projets immédiats, entre l'action des pouvoirs publics et le consensus social? Les auteurs des articles inclus dans le présent numéro de la revue ont consacré une part importante de leurs recherches aux processus politiques, économiques et sociaux qui ont fait évoluer la ville et son aire métropolitaine. Ils décrivent les situations complexes et d'échelles diverses que ce modèle a engendrées et discutent leurs conséquences.

Mots-clés: Barcelone, modèle Barcelone, planification stratégique, gouvernance.

\section{REFLEXÃO A PARTIR DAS RECENTES DINÂMICAS URBANAS DE BARCELONA}

Em 1994 a Finisterra dedicava um número ao sector terciário em resultado das transformações económicas e sociais nas aglomerações urbanas a partir das suas cidades-base: Lisboa e Barcelona (Barata Salgueiro e Carreras, 1994: 1). A internacionalização das economias, a terciarização e a competição entre cidades e a produção do espaço urbano, resultantes da apropriação do território pelas pessoas e organizações, eram então um tema inevitável. Atenta ao processo de terciarização da economia, ao aparecimento de novas formas de comércio, promoção imobiliária, turismo e consumo, a pesquisa geográfica deixava clara a urgência em compreender a dinâmica da capital da Catalunha no processo de internacionalização da sua base produtiva, para equacionar as perspectivas que se colocavam a Lisboa. Dada a abrangência das transformações em curso, as alterações nos modos de vida e hábitos de consumo estiveram então no centro das atenções, procurando-se compreender as lógicas do planeamento e das instituições, elementos-chave dos processos de mudança em Barcelona e críticos para a sua visibilidade no exterior. O notável reconhecimento internacional 
daquela cidade, marcadamente sentido nas décadas de 1980 e 1990, bem como as suas características urbanísticas e geográficas tornaram-se um referencial para muitas, entre elas, Lisboa.

Esta orientação da investigação geográfica resulta dos processos de transformação da economia mundial que se observam nos finais do século passado e se acentuam no século XXI, despoletando fenómenos de metropolização e, com eles, um reforço económico e financeiro dos centros de "comando mundial" (Sassen, 1991). Neste novo milénio, as cidades europeias saem de uma longa e intensa fase de crescimento ligado à industrialização do pós-guerra e procuram responder aos desafios resultantes das modificações profundas do contexto económico, social e ambiental. Por isso as políticas das cidades tornam-se mais ambiciosas e definem-se estratégias para aumentar a sua atractividade (Queirós, 2009).

Assim se explica porque, dezasseis anos volvidos, este assunto permanece central na pesquisa geográfica. Barcelona, como Lisboa, «teve o privilégio de nascer com miradouros naturais e de ter os pontos cardeais desenhados pela geografia» (Vásquez Montalbán, 1990: 12). Diz-nos, pois, este autor que a sul, o Mediterrâneo e os rios Bèsos e Llobregat, e a norte, a barreira de Collserola, onde se destaca Tibidabo, sinalizam referenciais que Hércules visionou quando ali chegou, segundo conta a lenda. Os primeiros habitantes destas terras cobertas por pequenas colinas (como Monterols ou a Muntanya Pelada) dominavam todos os caminhos, por mar ou por terra. Assim como Barcelona reclamou um olhar de Hércules para nascer, Lisboa buscou Ulisses na lenda das suas fundações. Cerzindo o horizonte da cidade, as sete colinas a norte (como a de S. Jorge ou de S. Vicente), e o estuário do Tejo que se funde com o oceano Atlântico, a sul, revelam uma povoação com uma localização estratégica privilegiada, que culminou num importante porto comercial. Suficientemente bem situadas para se desenvolverem e beneficiando de condições climáticas suaves, o crescimento urbano revela a sua evolução que, em ambos os casos, viria a compactar-se pelas colinas, cobrindo um território onde a natureza e a paisagem seriam fortes aliadas das suas populações.

Busquets (2004) considera Barcelona o protótipo de uma cidade europeia mediterrânea, em termos de densidade, compacidade e crescimento, características formais e processos de transformação histórica. Em Barcelona percepciona-se um tempo solidificado (Busquets, 2004: 18); os seus mais de 2000 anos de história estão incrustados no tecido urbano, revelando-se certos períodos mais criativos e inovadores do que outros, com projectos capazes de sobreviver a várias gerações, como o Eixample de Ildefonso de Cerdà (Busquets, 2004; Capel, 2005; Degen e García, 2008). No plano imaterial, Muñoz (2008b: 165) e Degen e García (2008: 22) acrescentam o estilo de vida mediterrâneo associado ao imaginário de mediterraneidade.

Em cada cidade, em cada projecto urbano, encontramos expressões do poder, riqueza, conflitos e debilidades dos seus mentores e construtores. Descobrimos também processos específicos da sua evolução e história cívica e outros projec- 
tos que são seguidos ou participados por muitas outras cidades. Centrando a atenção nos períodos mais recentes da história de Barcelona, as estratégias ligadas a grandes projectos mundiais associaram-se a eventos culturais, redefinindo formas urbanas, impulsionando a economia da cidade e a reflexão sobre um urbanismo crítico. São exemplos dessa transformação as intervenções na cidade a propósito das Exposições Universal de 1888 e Mundial de 1929 e, já no período posterior à restauração da democracia, os Jogos Olímpicos de 1992 e, em 2004, o Fórum Universal das Culturas. Do conjunto dos grandes eventos, as olimpíadas possibilitaram prestigiosas realizações, que atestam a capacidade de renovação da cidade através da recriação de uma imagem atractiva, dinâmica e competitiva (Capel, 2005; Borja, 2009; Queirós, 2009).

Perante o horizonte dos Jogos Olímpicos de 1992 - de acordo com Capel (2005), propostos em 1981 -, as transformações ocorridas nos finais dos anos 80 em Barcelona, sob um forte protagonismo da obra pública, reformaram a cidade e abriram-na ao mar, completaram a urbanização de Montjuïc, renovaram estruturas dos serviços subterrâneos e fecharam o anel de "rondas" (Dalt, Litoral), permitindo uma redistribuição do intenso tráfego metropolitano. Esta remodelação uniu o poder público com visão de futuro, capacidade de captação e de gestão de recursos, com a concepção cultural e arquitectónica adequada, nutrindo as ideias e projectando o desenho urbano, produzindo uma transformação memorável. Depois dos Jocs Olímpics, o Fórum das Culturas, inaugurado em 2004, iria ampliar a recuperação da frente litoral, associada ao restabelecimento ambiental de uma zona decadente junto da foz do rio Bèsos, possibilitando a implantação de uma nova marina e edifícios de exposições e congressos (Capel, 2005) e, mais recentemente, a iniciativa 22@.

Políticos e arquitectos de Barcelona foram os protagonistas das referidas mudanças (Moix, 2002; Muñoz, 2008b). Com eles, e com o apoio dos poderes económicos instituídos na Catalunha, deu-se início a uma nova etapa nas dinâmicas socioeconómicas da cidade e da área metropolitana. As actuações de reordenamento urbanístico permitiram o desenvolvimento do sector dos serviços e proporcionaram uma crescente internacionalização da base produtiva, postulando-se um modelo económico num novo contexto pós-industrial. Um contexto centrado no comércio e nos serviços avançados com elevada produtividade, evidenciando uma alteração de rumo no trajecto da história da cidade, em direcção a uma economia do conhecimento (Busquets, 2004; Clua e Albet, 2008). Porém, a estrutura profissional e política que consubstanciou a regeneração de Barcelona nos anos 90 chegou ao seu termo, tendo a iniciativa pública começado a diminuir, passando a fazê-lo com evidentes mais-valias para as empresas privadas.

Lisboa viveu um momento análogo e oportunidades e debilidades comparáveis. Na década de 1990, no limite oriental da cidade, junto ao Tejo, uma área urbana em degradação crescente foi alvo de um conjunto de operações económicas e intervenções urbanísticas, sob o pretexto de alojar uma exposição internacional, a Expo'98. Este evento simboliza em Portugal um momento 
memorável de regeneração urbana, recuperação ambiental e paisagística e um motivo de orgulho nacional. Sob o pretexto de um evento internacional, Lisboa mostrou vitalidade cultural e apresentou ao mundo a capacidade da arquitectura, desenho, engenharia e construção nacionais, no edificado estruturado que ergueu num terreno industrial decadente. Melhorando uma parte do estuário do Tejo, um importante património para o futuro foi reciclado, recompondo a dinâmica metropolitana da capital (Gaspar, 2008).

Depois deste evento, na década de 2000, inicia-se uma outra história, que a renovada imagem, as novas infra-estruturas e acessibilidades e as sinergias iniciadas, facilitaram. A cidade conheceria uma nova trajectória de operações de renovação, através de inúmeros projectos - previstos e em curso - de intervenção urbanística, de valorização e requalificação de edifícios e de áreas emblemáticas da cidade, como a Frente Ribeirinha da Baixa Pombalina, a Matinha, a Ribeira das Naus, o terminal de Cruzeiros, o desnivelamento do nó de Alcântara, o Capitólio do Parque Mayer, o projecto de instalação do centro cultural dedicado à arte africana contemporânea (Africa.Cont), o novo Museu dos Coches, a Fundação Champalimaud... Este conjunto de intervenções tem como objectivo recuperar o papel histórico e simbólico de certos sectores da cidade, restituir aos cidadãos espaços públicos de qualidade e criar uma "marca cosmopolita" (www.frentetejo.pt/; www.cm-lisboa.pt/). Esta dinâmica comporta assumidamente a valorização arquitectónica, ambiental e paisagística, a promoção da cultura e a dinamização turística de Lisboa (www.frentetejo.pt/; www.cm-lisboa.pt/).

De forma similar à vivida em Barcelona nos anos 80-90, os projectos em curso em Lisboa retratam o bom entendimento entre a política, a arquitectura e a cultura. Também em Lisboa, após o impulso da última exposição mundial do século XX, o colectivo - mormente representado por políticos e arquitectos - abre de novo os limites fechados da capital para o rio, a área metropolitana, o país e o mundo. Este novo relacionamento é uma consequência da deslocalização industrial e da decadência das funções portuárias: finalmente, as grandes obras públicas vão centrar-se na recuperação do património, na eliminação das barreiras que separam os cidadãos do rio, devolvendo qualidade ao espaço público, procurando desenvolver o turismo, abrindo a cidade aos visitantes e associando-a a eventos culturais. Esta viragem é acompanhada pelo fortalecimento de Lisboa na sua relação com a Europa e o mundo, sobretudo com o "Sul global".

Assim como sugere o tema central da Expo'98, sobre os oceanos, a diversidade e função essencial de Lisboa no equilíbrio planetário, os projectos em curso (e a iniciar), que se estendem do centro histórico à frente ribeirinha oriental, sul e ocidental, traduzem-se em operações de regeneração urbanística, no resgate do património e no relançamento da economia urbana, procurando uma imagem equilibrada e diversificada da cidade, uma projecção internacional e a sua devolução à população. Estas ideias estratégicas são acentuadas no novo Plano Director Municipal de Lisboa, que aposta na valorização da frente ribeirinha como expoente da imagem da cidade, o seu ex-libris (Expresso, 17/07/2010). O campeonato europeu de futebol em 2004, a entrada de Lisboa no destino das 
companhias de aviação low cost e uma oferta hoteleira ampliada, converteram a capital na principal atracção turística do país. Ao pacote de eventos internacionais de que Lisboa tem sido palco, junta-se a assinatura do Tratado de Lisboa, a Cimeira UE-África em 2007, a cimeira Luso-Brasileira em 2010 e a cimeira da NATO, bem como a Volvo Ocean Race com a regeneração da doca de Pedrouços.

A dinâmica económica do período "pós-Expo" perdeu, todavia, o seu fulgor nos finais de 2000 o que obrigou, tal como aconteceu em Barcelona, a renovadas e engenhosas parcerias público-privadas. É precisamente porque nos encontramos num momento de crise económica, de endividamento e de níveis elevados de desemprego que existe o risco do "fecho" das perspectivas de expansão e de regeneração da cidade, ou do condicionamento dos poderes públicos perante os interesses privados; por isso, importa olhar de novo para Barcelona e procurar aprender com a sua experiência. Como diria Busquets (2004), aprender na perspectiva das oportunidades e das debilidades, alertando para as circunstâncias históricas singulares da experiência de Barcelona correspondentes à recuperação da democracia, ao importante papel das associações de "vizinhos", à relação frutuosa entre políticos, arquitectos e engenheiros e à dimensão operativa do urbanismo; ou, como previne Capel (2005), aprender na perspectiva optimista e realista. Quer com isto dizer o autor que é possível mudar uma situação de grandes défices urbanísticos, ou seja, «há sempre solução para os problemas das grandes cidades, mas isso exige tempo e determinadas condições sociais, económicas e políticas» (Capel, 2005: 21).

Busquets e Capel são unânimes em afirmar que não há modelos gerais e, portanto, «o que se passou em Barcelona não serve para copiar para fora da cidade» (Capel, 2005: 25). No entanto, a experiência de Barcelona deve ser conhecida porque, e resumindo Busquets (2004: 352-354), neste caso as actuações se caracterizaram por uma alteração da escala de intervenção dos projectos (assente em grandes projectos urbanos), que passaram a ser integrados (sectorial e territorialmente), e pelo facto da liderança das intervenções, apesar de pública, surgir em parceria com o sector privado. Esta mudança de regime de actuação engloba aspectos tão diversos como: um desempenho que implica a participação popular e a coesão social; a capacitação que a melhoria do espaço público traz no processo de desenvolvimento social e económico; a descentralização municipal com a cooperação da administração pública, universidades e empresas privadas; e a gestão integrada da mobilidade e o planeamento estratégico, entre outras dimensões.

Ao interpretar Barcelona como um laboratório urbano e social, fruto de um urbanismo entendido como projecto, estamos perante um referencial empírico, integrado, e centrípeto (Montaner, 2004), onde a renovação, iniciada nos finais dos anos 1980 e durante os anos 90, produziu um salto qualitativo derivado do talento dos técnicos municipais, gestores e políticos que nela intervieram. Este argumento forte explica que o referido laboratório seja um objecto de estudo apaixonante. Tendo-se tornado um ícone dos processos complexos 
de planeamento e de construção continuada de uma cidade, serve de lição para outras cidades que, do ponto de vista do método e da gestão, muito podem aprender - mesmo que o modelo não seja perfeito, já que o debate intelectual e as críticas recorrentes apontam para um défice de discussão aberta com os actores sociais, uma carência de componentes para um "urbanismo verde", e os limites da fórmula barcelonesa, muito centrada na cidade municipal esquecida da Barcelona metropolitana (Monclús, 2003; Trenc, Cebollada e MirallesGuasch, 2008).

Este laboratório (a cidade) coloca a descoberto um tema igualmente importante, já que ela surge como "actor político", o que significa que estão a aparecer novas formas de fazer política de cidades. Com a globalização, essas políticas sofreram uma transformação nos seus objectivos, descurando o bem-estar e a política social, para se concentrarem em temas como a estratégia económica e a competitividade o que lhes permite manterem-se na cena global (Degen e García, 2008).

\section{A CULTURA “DO PROJECTO URBANO” EM BARCELONA COMO MOTOR DE GOVERNANÇA}

Importa fazer uma reflexão sobre a importância da estratégia territorial nas transformações recentes em Barcelona; com efeito, o planeamento estratégico constituiu o dispositivo organizador das actuações, inicialmente da cidade e depois da área metropolitana. Barcelona é hoje o centro nevrálgico de uma rede de cidades. A sua economia de serviços está em processo de expansão, embora ainda com forte representação da indústria, a base económica tradicional da cidade e da sua envolvente metropolitana.

A constatação da realidade metropolitana induziu a necessidade de planear um território que vai muito além das fronteiras administrativas da cidade (Neves, 1996; www.cideu.org). Assim, em 1988 constituiu-se a associação do plano estratégico de Barcelona, em 1990 dava-se início ao primeiro Plano Estratégico de Barcelona (PEB) seguido, em 1994, pelo segundo PEB e, em 1999, pelo terceiro PEB, marcando uma fase de actuação abrangendo exclusivamente a cidade de Barcelona. Numa segunda fase, o PEB alarga a sua área de acção, incluindo nela o território metropolitano e, em 2003, era aprovado o primeiro Plano Estratégico Metropolitano de Barcelona (PEMB); este foi revisto em 2007 e desde 2008 está em vigor um Novo Modelo de Desenvolvimento da AMB (www.bcn2000.es).

Actualmente, o PEMB é feito por uma associação privada sem fins lucrativos promovida pelo Ajuntament de Barcelona (Câmara Municipal de Barcelona), integrando os 36 municípios da área metropolitana. Congrega os interesses de mais de 300 instituições públicas e privadas, que actuam na área metropolitana: Câmara de Comércio, Círculo de Economia, União Geral dos Trabalhadores da Catalunha, Universidade de Barcelona, Feira de Barcelona, Consórcio da Zona 
Franca de Barcelona, Porto de Barcelona, Governo Regional Autónomo da Catalunha, Conselhos Comarcais, Entidade Metropolitana de Transportes e de Ambiente,... (www.cideu.org). O PEMB constitui um documento orientador dos investimentos estratégicos de desenvolvimento (infra-estruturas; comunicação; ambiente; urbanismo; investigação; etc.), da cidade e da região envolvente, orientados por um modelo e uma visão para um horizonte alargado (2020), que se prevê concretizar através de cinco eixos (governança e redes; referência global; qualidade social; infra-estruturas; sustentabilidade). Os consensos surgem em sede de um fórum, onde se debatem ideias e políticas. Na actualidade, estão em curso cerca de 80 projectos estratégicos metropolitanos classificados por "blocos" (em sintonia com os eixos): conhecimento; mobilidade e acessibilidade; promoção de sectores estratégicos, infra-estruturas e equipamentos de impacto urbano; sustentabilidade e ambiente; urbanismo e coesão social (www.bcn2000.es). A metodologia de trabalho da associação (municípios e outras instituições públicas e privadas) baseia-se em consensos, na liderança partilhada e na cooperação entre os actores que participam no desenho das estratégias.

Igualmente interessante é verificar que desde o primeiro PEB «a atribuição de recursos se orientou a partir dos projectos e não dos planos» (Muñoz, 2008b: 153). Monclús (2003) afirma que a cultura do projecto urbano se manifesta logo nas primeiras publicações do Ajuntament, nos anos 1980. A actuação por projecto, também apontada como característica da política urbana daquela época por Muñoz (2008b), baseou-se em coligações entre os sectores público e privado, como um reconhecimento mútuo da importância da vontade política no estímulo à esfera económica da cidade, desenvolvendo uma cultura de confiança e catalisando o envolvimento dos cidadãos. Estes consensos facilitaram, por sua vez, o planeamento estratégico. Segundo Degen e García (2008), o modelo em que todos se reconheceram ficou estabelecido no terceiro Plano Estratégico de Barcelona (PEB) sendo a cumplicidade entre actores essencial, como se verificou nos acordos entre a câmara do comércio, os sindicatos e as entidades patronais, para a implementação de diversos projectos de infra-estruturas de transportes.

$\mathrm{Na}$ qualidade de presidente da Fundación Ciudadania y Buen Gobierno e director das Estratégies de Qualitat Urbana, Pascual i Esteve (2007: 93) define o planeamento estratégico de Barcelona como uma operação específica centrada no desenvolvimento socioeconómico que se inscreve num contexto de uma nova forma de governar a cidade e o município, e que aprofunda a democracia, assente na sustentabilidade ambiental, equidade social e crescimento económico. Na sua perspectiva, uma das grandes inovações do planeamento de Barcelona é o carácter integrador da actuação urbanística - transversal e territorial - resultante da cooperação institucional pública e privada e da participação cidadã (Pascual i Esteve, 2007). Esta concepção de plano estratégico constitui uma das formas de desencadear a governança territorial, através de um novo tipo de modelo de gestão do território: a gestão relacional ou de redes. Para que esta fosse possível foi necessária a identificação dos projectos estruturantes da transformação urbana, na perspectiva de construção colectiva do território e com amplo reconhecimento social. 
Mais notável ainda na experiência do planeamento estratégico de Barcelona, é um trabalho de desenho e recuperação arquitectónica e urbanística, que se desenvolveu num processo concomitante e consecutivo em diferentes escalas, que Busquets (2004: 350-411) identifica e agrupa segundo três blocos de actuação: reabilitação urbana, associada a actuações de menor escala e que reflectem, quer uma intervenção em espaços urbanos, livres e espaços verdes, quer uma actuação por partes; a reestruturação urbana, que implica estratégias de maior alcance, relacionadas com a rede viária e a as áreas de novas centralidades; por fim, as chaves estruturais da forma urbana de Barcelona.

De acordo com Busquets (2004), no primeiro bloco, são exemplos materiais, o parque urbano el Clot, a praça Salvador Allende, ou a avenida de Gaudí. Merece ainda uma especial referência a recuperação da Rambla de Poblenou e da Ciutat Vella (El Raval, Santa Caterina e Barceloneta ${ }^{2}$ ). No segundo bloco incluem-se as transformações relacionadas com projectos viários, conhecidos por nó da Trinitat, Rambla de Prim, Moll de la Fusta, Via Júlia, Praça das Glories e as Rondas, bem como, na posição de centros, a Rambla e a Via Llaietana, a praça de Sant Jaume, e também o "quadrilátero" plurifuncional (Montaner, 2004) formado nas extremidades pelas áreas olímpicas (o Anel Olímpico na parte alta de Montjuïc, a Vila Olímpica junto da cidadela - Ciutadella) e que avança em cunha para a frente de água da cidade, o Vall d'Hebrón no norte da cidade e a Área Diagonal que sistematiza os espaços circundantes da área desportiva privada da cidade; na área metropolitana foram feitas, entre outras, intervenções nas cidades de Sabadell e Badalona. No terceiro bloco, cabem por exemplo, obras de grande repercussão para a imagem da cidade, como a construção da Vila Olímpica ou a abertura da Diagonal até ao mar, favorecendo a reorganização de extensas áreas anteriormente industriais (Oliva, 2003).

Daqui redunda uma outra característica do planeamento estratégico que Busquets (2004) assinala, ao considerar que todas as intervenções resultaram de um processo de actuação em diversas escalas que, de certo modo, se sobrepuseram e se sucederam. Completar a forma da cidade resolvendo as suas deficiências, configurar o quadrado urbano (área olímpica) segundo uma lógica simultaneamente multifuncional e de especialização urbana (mas que no futuro se converteria em áreas de serviços de toda a cidade), planear vias de conexão, renovar elementos aglutinadores, bem como conceber as "áreas de nova centralidade" (segundo Montaner, 2004, ideia promovida por Joan Busquets em 1987) foram as intervenções essenciais em Barcelona até às olimpíadas, seguindo uma gestão multiescalar e multiactores.

Conforme Pascual i Esteve (2007) e Degen e García (2008), na base do planeamento deste tipo de operações especiais, a cidade é equacionada, por um lado, como "uma empresa" (a cidade empresarial de Asher, 1995), já que os

2 Sobre a intervenção neste sector da cidade, em particular no El Raval, Barri Gotic, Santa Caterina e Barceloneta, uma reflexão mais alargada pode encontrar-se em Queirós (2009). 
gastos públicos e particularmente os municipais são desacelerados, dando origem ao new management como estratégia central da administração pública (criando uma visão, partilhando o poder, construindo redes de relações, liderando as acções,...). Por outro lado, surge dominante uma cultura de projecto centrada nas infra-estruturas e serviços de comunicação e de informação (na economia do conhecimento), tidos como os motores do desenvolvimento social e económico. A cultura de projecto associa-se, como referido, a um modelo relacional de gestão urbana.

Convém lembrar que o papel tradicional da administração pública enquanto garante do bem-estar, provedora de recursos, equipamentos e serviços públicos se alterou nos anos 1980, ao surgirem unidades de gestão municipal mais autónomas, dotadas de objectivos específicos e de pressupostos de descentralização territorial dos processos de decisão. Na década seguinte, emergem mais alterações, com a introdução de critérios de gestão empresarial dos assuntos públicos e, em especial, de empresas privadas na gestão dos serviços públicos, criando-se mercados para alguns dos serviços municipais (Queirós, 2002; Pascual i Esteve, 2007). Em resultado, actualmente, na maioria dos municípios, quer em Espanha quer em Portugal, são práticas comuns a contratação externa de serviços municipais, a cooperação das administrações públicas municipais com a iniciativa privada, bem como a cultura da competitividade dos serviços públicos orientados para a eficiência, a qualidade e a prestação de contas ao cidadão, numa lógica de proximidade. A empresarialização dos serviços públicos associa-se a entidades de capital de risco ou capital de semente, com um modelo de financiamento misto de grandes infra-estruturas e equipamentos públicos (Pascual i Esteve, 2007). O planeamento estratégico, iniciado em Barcelona há mais de 20 anos, é assim o fruto das alterações que se observam na "nova" gestão pública, no exercício das suas funções - promotora e organizadora - de construção colectiva do território.

Por tudo o que ficou exposto, a cultura de projecto e o processo de planificação estratégica iniciado com o primeiro PEB foram eleitas "boas práticas" para aplicar nas cidades latinas, americanas e europeias (Moix, 2002; Busquets, 2004; Capel, 2005; Pascual i Esteve, 2007). Segundo Pascual i Esteve (2007: 101), a transformação liderada pelo Ajuntament conseguiu «converter uma cidade pouco conhecida numa cidade de vanguarda ao nível mundial»; o modelo de gestão das transformações desta cidade é motivo de estudo por parte de outras que almejam o mesmo protagonismo. Tal como Capel e Busquets, também Pascul i Esteve adverte que o que deve ser copiado é a capacidade para adoptar uma metodologia própria e adequada à situação económica e social de cada cidade.

Merecem ainda reflexão alguns aspectos singulares que estimulam a cultura de projecto, que se observa em Barcelona: crescimento económico e recursos próprios, forte dinamismo populacional com acentuada imigração nacional e de países terceiros, emergência da sociedade de informação, projecto de futuro e de internacionalização e competências históricas da Câmara Municipal com 
grande protagonismo e tradição reconhecida de planeamento urbano (existe desde 1974 um Plano Geral Metropolitano, PGM) e marketing. «A reinvenção de Barcelona não tem nada de novo» já que no historial da cidade existe um vasto acervo de acontecimentos culturais de desenvolvimento da paisagem urbana (Degen e García, 2008: 11). A grande transformação ocorre porque a cidade deixa de ser um centro de produção para se converter num pólo de consumo. As autoras afirmam que a comercialização de Barcelona girou em torno do desenho, arquitectura e forma de vida associada ao "estilo mediterrâneo". Muñoz (2008a e 2008b) chamou-lhe processo de "brandificação", um arquétipo do modelo de cidade mediterrânea, "pós-moderna", eficiente, tecnológica, sustentável, social e culturalmente avançada. Uma outra das suas particularidades é a capacidade dos seus actores encetarem projectos adaptados ao contexto na economia global (Queirós, 2009). Barcelona tem procurado que as estratégias de transformação territorial, como se afirma no mais recente PEMB, assentem em lógicas «desde los proyectos y la acción estratégica» (www.ben2000.es).

O PGM de 1974 pressupunha uma ordem territorial a partir da regulação dos espaços públicos, em particular, visando melhorar o sistema de transportes e as zonas verdes; graças à sua qualidade, e apesar de modificações sucessivas, a sua essência não foi alterada (Degen e García, 2008). Com ele financiaram-se pequenos e grandes projectos, como a qualificação de bairros ou os jogos olímpicos. Um outro aspecto marcante do planeamento em Barcelona é que atendendo aos recursos limitados, as reformas foram feitas com o auxílio dos Planos Especiais de Reforma Interna (PERI) que permitiram, na maioria dos casos, a participação de associações de moradores no desenho das áreas afectadas, estimulando as identidades de bairro. Já no que se refere ao projecto olímpico, planeou-se uma dupla estratégia de ampliação do papel da cidade na economia global, e na afirmação da vocação de liderança metropolitana, ao mesmo tempo que se implementaram projectos transversais e integrados, como o que se verificou em toda a frente marítima.

O êxito do projecto integrador da construção da vila olímpica, ou o da regeneração da Ciutat Vella (e muitas outras intervenções já referidas), deve-se ao facto de serem projectos que, segundo Cohen (1998), se fundaram numa ruptura consciente com o planeamento funcionalista (fig. 1). Assim, os projectos em Barcelona passaram a estar centrados em praças, ruas e bairros, em vez de em espaços públicos, de circulação e zonas de habitação; em seu entender, Barcelona tornou-se num "cemitério" para os conceitos simplificadores do urbanismo da Carta de Atenas. Cohen (1998) chama ainda a atenção para outro detalhe: o "tempo" dos projectos de Barcelona é outra das suas características singulares por escaparem aos ciclos políticos dos mandatos eleitorais, integrando temporalidades bem maiores. Cohen, concretizando e antecipando Busquets, Capel e Pascul i Esteve, conclui que as fórmulas utilizadas em Barcelona podem ser repetidas e as estratégias urbanas reproduzidas; o que não é transportável é esta integração entre a cultura arquitectónica e a identidade colectiva. Estamos, por isso, perante uma experiência colectiva, um modelo não formal ancorado na 

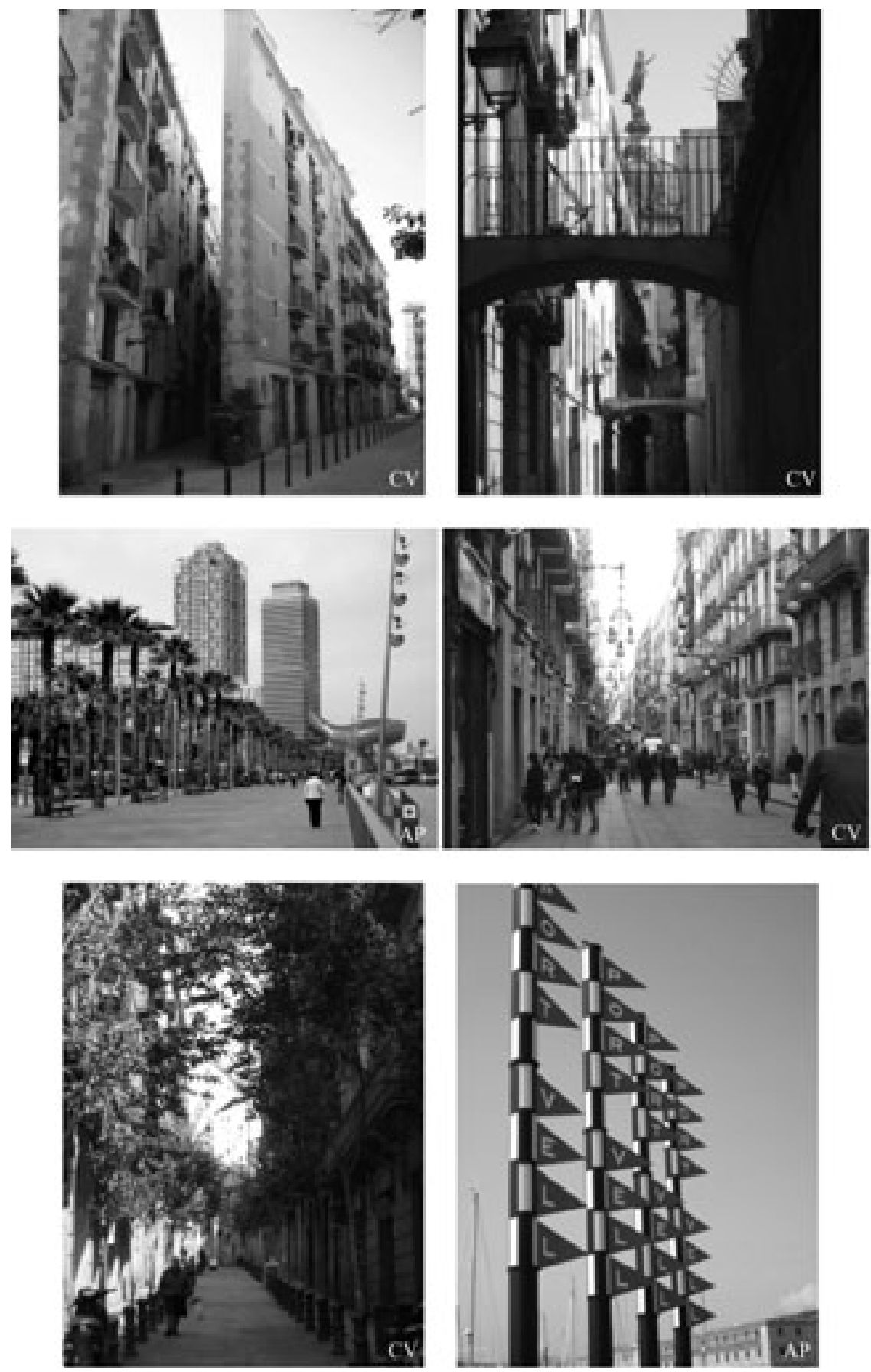

Fig. 1 - Cidade Velha (CV)/Antiga área portuária (AP).

Fig. 1 - Old district/old harbor. 
democracia urbana local, capaz de reajustamentos recíprocos e sem renúncia às competências respectivas.

Retomando Pascual i Esteve (2007), o processo de planeamento estratégico em Barcelona é feito em colaboração, o que constitui uma sólida base para o desenvolvimento da governança urbana. Assim, Barcelona - entre diferentes entendimentos e perspectivas sobre a cidade, construindo e consolidando pontes (Seixas, 2008) - dispõe de prática em gestão de redes de actores e de projectos complexos, bem como experiências de relacionamento com a sociedade civil organizada. A par de um planeamento estratégico integrado, ainda se desenvolveram planos estratégicos sectoriais, como o plano da cultura, o projecto educativo para a cidade, o plano de desporto, o plano de serviços sociais e o plano de turismo, revelando a capacidade para multiplicar instrumentos de planeamento. E os planos estratégicos foram postos em prática e associaram-se a entidades para elaborar e gerir as estratégias urbanas; estas instituições alargaram o leque de representantes nos processos de decisão e, em contrapartida, impulsionaram a gestão estratégica no governo da cidade. Porém, necessitaram de um forte reconhecimento das administrações públicas e ganharam legitimidade, à medida que nas estratégias de desenvolvimento da cidade também participaram os cidadãos - se bem que nem sempre com grande fluidez e encapsulando tensões sociais (Cruz-Gallach, 2008).

\section{DESAFIOS POSTERIORES AOS JOGOS OLÍMPICOS DE BARCELONA}

O projecto "especial" dos Jogos Olímpicos de Barcelona surgiu ainda nos anos 1980, como uma oportunidade de renovação, um esforço de cooperação entre sectores, tendo-se encetado novas formas de gestão urbanística (por exemplo, criação de órgãos específicos) com atributos de uma organização mais eficiente. Barcelona tornou-se um destino turístico e um enclave cultural de referência (Garcia-Ramón e Albet, 2000). Todavia, no contexto pós-olímpico, em meados dos anos 1990, a posição de Barcelona, como centro da economia financeira e de serviços no ranking de cidades era frágil (Degen e García, 2008). Alguns autores são de opinião que o modelo seguido até ao culminar das olimpíadas veria terminados os seus dias na década de 2000, perdendo a sua homogeneidade, coerência e equilíbrio territorial, atributos baseados nos elementos conceptuais de renovação do desenho, arquitectura e urbanismo da cidade; nas palavras de Montaner (2004), perdeu-se a anterior capacidade para interpretar e gerir a cidade o que remete para a questão que se refere aos "limites" do modelo (Casellas, 2006).

Nos anos 80, a actuação em cada área específica transformou a cidade, cosendo os limites entre os fragmentos urbanos, obtendo-se uma «continuidade urbana, sem que se tenha elaborado um plano urbanístico a priori» (Muñoz, 2008b: 153). Porém, aos poucos, os objectivos fixados pelas políticas urbanas 
na transição democrática foram sendo substituídos por processos de regeneração de grandes sectores urbanos. Em lugar da intervenção assente na "sutura" entre bairros, surgem os projectos temáticos de grande escala para criação de centralidades urbanas, dando lugar ao que Muñoz (2008b) identifica como mudança de ciclo no que respeita ao pensar e intervir na cidade.

Desde então, as intervenções efectuadas em Barcelona são apontadas como objectos sem relacionamento entre si, efeito de decisões e intervenções opacas, porque não resultam do consenso e do debate público. Montaner (2004) associa esta fase a um urbanismo difuso, fragmentado, inacabado e inexplicável. Vai mais longe na crítica, ao esclarecer que a tendência que se observa nas intervenções do Ajuntament é a de privilegiar a grande escala de implicação, associada a operações controladas por grandes empresas privadas, revelando a incapacidade de se impor e escutar as reivindicações dos movimentos sociais. Na sua opinião, a excepção a este urbanismo obscuro salpicado por objectos isolados é o plano 22@, em Poblenou (que à frente se apresentará), que se implementa de forma flexível e se adapta à morfologia existente e ao passado industrial e social do bairro (Montaner e Muxí, 2002; Montaner, 2004).

Mas o expoente máximo da alteração de direcção do "modelo Barcelona" é - também apontado por Capel (2005) - conotado com o Fórum das Culturas, em 2004. Montaner e Muxí (2002: 264) estabelecem uma analogia que por si explica a crítica: de uma «cuidadosa acupunctura num tecido urbano para uma metodologia de aplicação de prótese de proveniência estranha». A área de intervenção que corresponde ao referido projecto encontra-se no limite oriental da cidade, numa frente marítima, de 180 ha perto da foz do rio Bèsos, onde também se localizam uma estação de águas residuais, duas centrais termoeléctricas, uma incineradora de resíduos urbanos e um bairro crítico pelo seu isolamento e marginalidade social, conhecido por la Mina. Nesta área do edifício do Fórum encontram-se actualmente o Centro de Convenções e de Congressos de Barcelona (com capacidade para 20 mil congressistas), o centro comercial Diagonal Mar, e edifícios (arranha-céus) de hotéis, escritórios e habitação de luxo (fig. 2).

Com este projecto pretendia-se encerrar algo iniciado com as olimpíadas, dando-lhe uma vocação cultural e integrando ao mesmo tempo equipamentos ambientais situados no limite da cidade. Esta intervenção não sutura partes fragmentadas da cidade, pois altera profundamente a paisagem e os usos. Para Muñoz (2008b) trata-se de uma operação de "terciarização intensiva", destinada a segmentos com poder de compra, recordando modelos de urbanização do tipo resort (como Miami) e excluindo toda a ideia de cidade integradora, quer do ponto de vista social, quer urbanístico.

A controvérsia gerada com o urbanismo, que aqui se implementou, demonstra que não corresponde ao "modelo Barcelona", pois resulta ele próprio de uma importação dos modelos norte-americanos. Com efeito, o Ajuntament não tinha mais soluções nem capacidade financeira - de acordo com Montaner (2004), apresentava uma enorme dívida - para dar continuidade ao modelo que culminou 

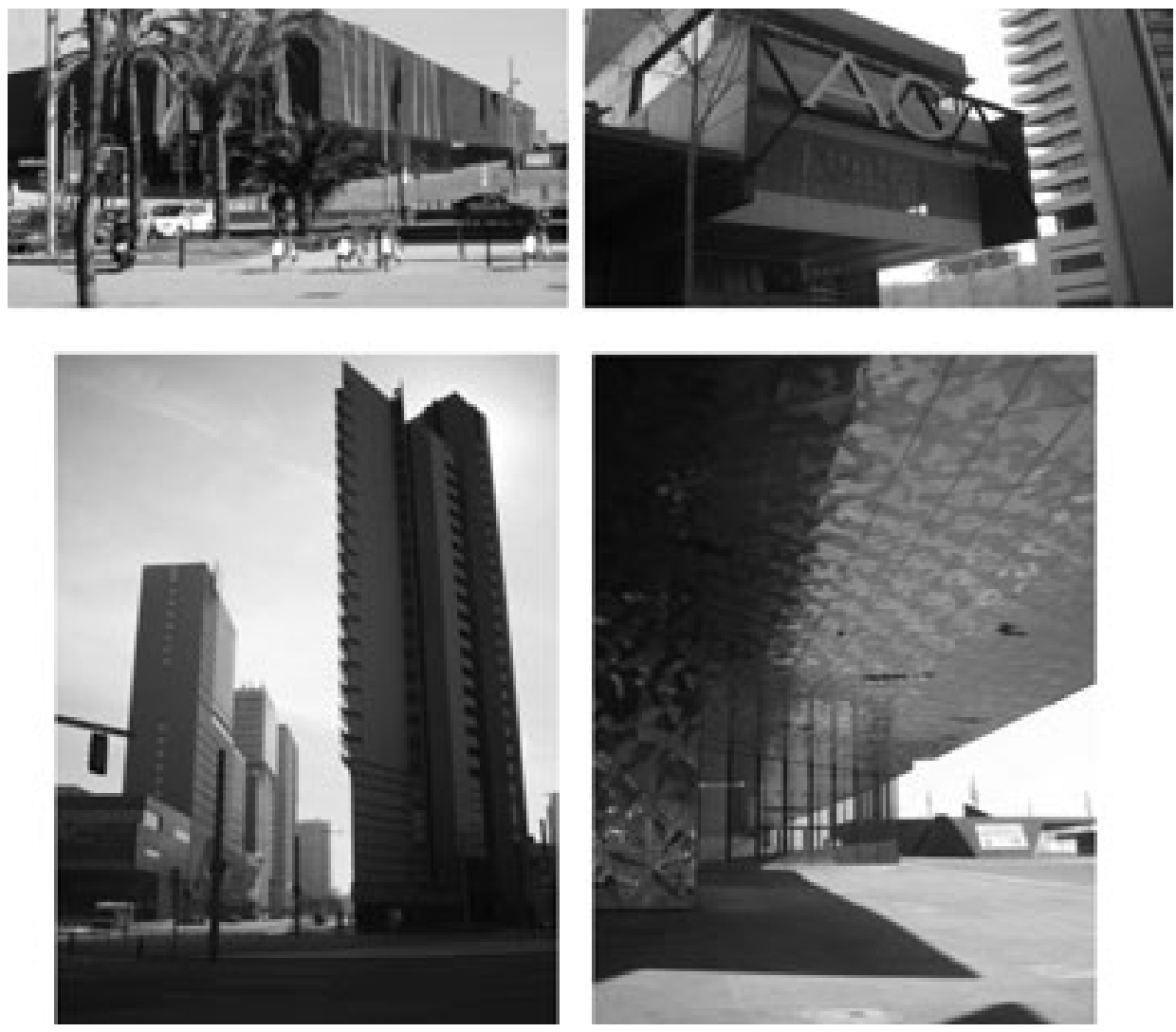

Fig. 2 - Área do «Forum de las Culturas».

Fig. 2 - «Forum de las Culturas» Area.

com os Jogos Olímpicos. A mudança de rumo será simbolicamente marcada pela exposição Barcelona New Projects; a partir daqui o município sucumbe aos grandes grupos imobiliários privados (como aconteceu com o grupo Hines). Uma observação atenta revela que a Câmara Municipal deixa a descoberto a sua enorme debilidade face ao projecto de desenvolvimento "Diagonal Mar", que se desenhou para a área do Fórum, onde hoje encontramos a Illa del Mare e a Illa de la Llum, que correspondem a duas das cinco fases residenciais deste mega-projecto, a Illa del Cel, que é um hotel e um complexo de apartamentos, e a Torre Diagonal Mar, um complexo de escritórios junto da frente marítima. À parte da remodelação da Rambla de la Mina, o bairro continua sem melhorias substanciais nas condições de habitabilidade (carência de equipamentos, insegurança, imagem negativa do bairro...).

A área tem como principal aspecto positivo o facto de ter mantido equipamentos problemáticos (incineradora de resíduos e estação de tratamento de águas residuais), e de procurar albergar áreas de lazer - projectos de náutica, zoo 
marítimo e um campus universitário. Apesar da contrapartida materializada na valorização de uma área com problemas ambientais, o efeito do investimento estrangeiro aqui realizado foi perverso: o seu resultado na emoção e no comportamento é o oposto ao previsto. A paisagem resultante é asséptica, elitista, deserta de vida local, uma porção de cidade descartável, "sem alma", em tudo se parecendo com qualquer espaço urbano norte-americano, revelando uma verdade trágica que é a da banalização da cidade de Barcelona (Queirós, 2009). Contrariando toda a lógica de regeneração de Barcelona, assente em morfologia e volumetria próprias, bem como o conceito de espaço público usado até então, esta intervenção não condiz com o imaginário de "mediterraneidade", antes se impõe com um skyline nada habitual nesta cidade, que poderia encontrar-se em qualquer cidade nos EUA.

As grandes diferenças entre os projectos em torno das olimpíadas e outros mais recentes - como o do Fórum - residem nos objectivos das políticas do município que parecem ter-se reduzido a facilitadoras do investimento das empresas privadas e na aceleração de certos processos de mercantilização crescente e que correspondem, no entender de Montcús (2003), a um urbanismo "globalizado" ou, no de Muñoz (2008b: 169), a um processo de «brandificación urbana». Agora a justificação da transformação urbana passou a ser a iniciativa cultural: com o objectivo de fomentar a interculturalidade, o Fórum das Culturas teve até o apoio da Unesco. Mas a diversidade e inclusão parou por aqui, pois o desenho do projecto e a sua programação não foram discutidos pela sociedade civil. Esta "segunda abertura" para o mar foi planeada de forma muito diferente da dos Jogos Olímpicos: promoveu-se mais o consumo da cultura e esqueceu-se a construção activa de uma cultura urbana (Degen e García, 2008). Capel (2005: 82) refere que «no projecto Diagonal Mar se previa a presença de sectores de residência popular». Este objectivo não foi cumprido, pois não se construiu habitação social e «permitiu-se que empresas imobiliárias se apropriassem das mais-valias geradas». Com a agravante de ter havido destruição das identidades históricas, alteração do tecido social, banalização da paisagem - «no se trata solo de modernidad; el problema puede verse desde otro prisma: la presión inmobiliaria lo arrasa todo» (Capel, 2005: 83).

Os críticos mais ferozes deste urbanismo de Barcelona são unânimes em afirmar que, por enquanto, este ambicioso projecto não facultou à cidade uma "nova centralidade" porque o espaço gerado privilegiou certos segmentos populacionais e se esqueceu que o verdadeiro sucesso de uma cidade reside no facto de criar praças, ruas e edifícios plurais e multifuncionais e com adequada escala humana.

A excepção a esta fórmula de intervenção está no projecto de transformação urbana conhecido por "22@”" para o bairro de Poblenou - outrora a alavanca industrial da Catalunha. O seu longo passado industrial está patente na concentração espacial de antigas fábricas (têxtil, química...), hoje visível pela quantidade de chaminés que se assinalam na paisagem urbana (Queirós, 2009). O bairro de Poblenou situa-se no sector sul de Barcelona, "encravado" entre a Vila Olímpica 
(agora conhecida por Nova Icária) e o Fórum 2004, e encontra-se, desde 2000, em processo de transformação urbana (Anuari Territorial de Catalunya, 2007).

A ideia matriz do Ajuntament foi promover um think-thank (que juntou um grupo de políticos, arquitectos, urbanistas, sociólogos, geógrafos, etc.), do qual resultou o embrião do 22@ (um projecto de transformação do bairro de Poblenou orientado para a sociedade do conhecimento); um primeiro documento seria elaborado pelo gabinete de estudos urbanísticos da Câmara Municipal de Barcelona, em meados dos anos 1990 (Oliva, 2003). Como Poblenou tinha sido uma área dedicada à actividade produtiva, era necessário dar-lhe um novo impulso, criando instrumentos de revitalização económica; a sua localização, muito central na cidade, seria certamente motivadora de uma intervenção apelativa para o mercado (Pareja-Eastaway et al., 2008). Assim, surge a ideia de transformação deste antigo sector industrial, já em decadência, num novo "distrito" digital, capaz de dotar a cidade de actividades orientadas para a economia do conhecimento, consolidar as actividades criativas e culturais já existentes e atrair novas indústrias criativas (fig. 3 ).

Nasce então o Plano 22@bcn, que tomaria forma no terceiro PEB, propondo a transformação dos quase 200 ha de solos já degradados e desqualificados, que albergavam o remanescente dos solos e das naves industriais (solos classificados por "22a" pelo Plano Geral Metropolitano, PGM), num novo distrito altamente qualificado e tecnológico (engenhosamente redenominado de 22@ já que usa a classificação do PGM para os solos industriais), um espaço produtivo assente no conhecimento, criatividade, talento e inovação, com a novidade de prometer a coabitação com a função residencial e dotado de equipamentos sociais (Queirós, 2009).

A renovação das áreas industriais de Poblenou criaria novos espaços produtivos, procuraria aumentar o emprego, edificaria novas residências de protecção social, novos equipamentos e zonas verdes. A aposta no 22@ corresponde a uma concepção da geografia económica da cidade, que se perfila como um dos aspectos mais inovadores de Barcelona; 22@, uma concepção que, segundo Borja (2009), facilita a passagem da velha indústria à nova economia, e se tornou o ícone das operações urbanísticas de regeneração da cidade da década de 2000, resultantes de parcerias público-privadas para investimentos em infraestruturas físicas, e das apostas em novas actividades e emprego associados à sociedade do conhecimento. Hoje em Poblenou aposta-se na atracção, por exemplo, dos new media, das TIC, das energias renováveis...

Enquanto plano de renovação urbana,o 22@ delimita no seu interior seis âmbitos territoriais (Llull Pujades Llevant, Perú-Pere IV, Campus Audiovisual, Parc Central, Eix Llacuna e Llul Pujades Ponennt) e com o exterior procura a articulação com outras áreas da cidade: por isso, encontra-se associado a importantes realizações a norte do bairro, como é o caso de Sant Andreu-Sagrera, onde chegará o comboio de alta velocidade, e as intervenções de qualificação urbana na praça das Glories, tudo isto formando uma "triangulação" com o Fórum das Culturas 2004 (22@barcelona, 2005). Através do plano 22@, o bairro 

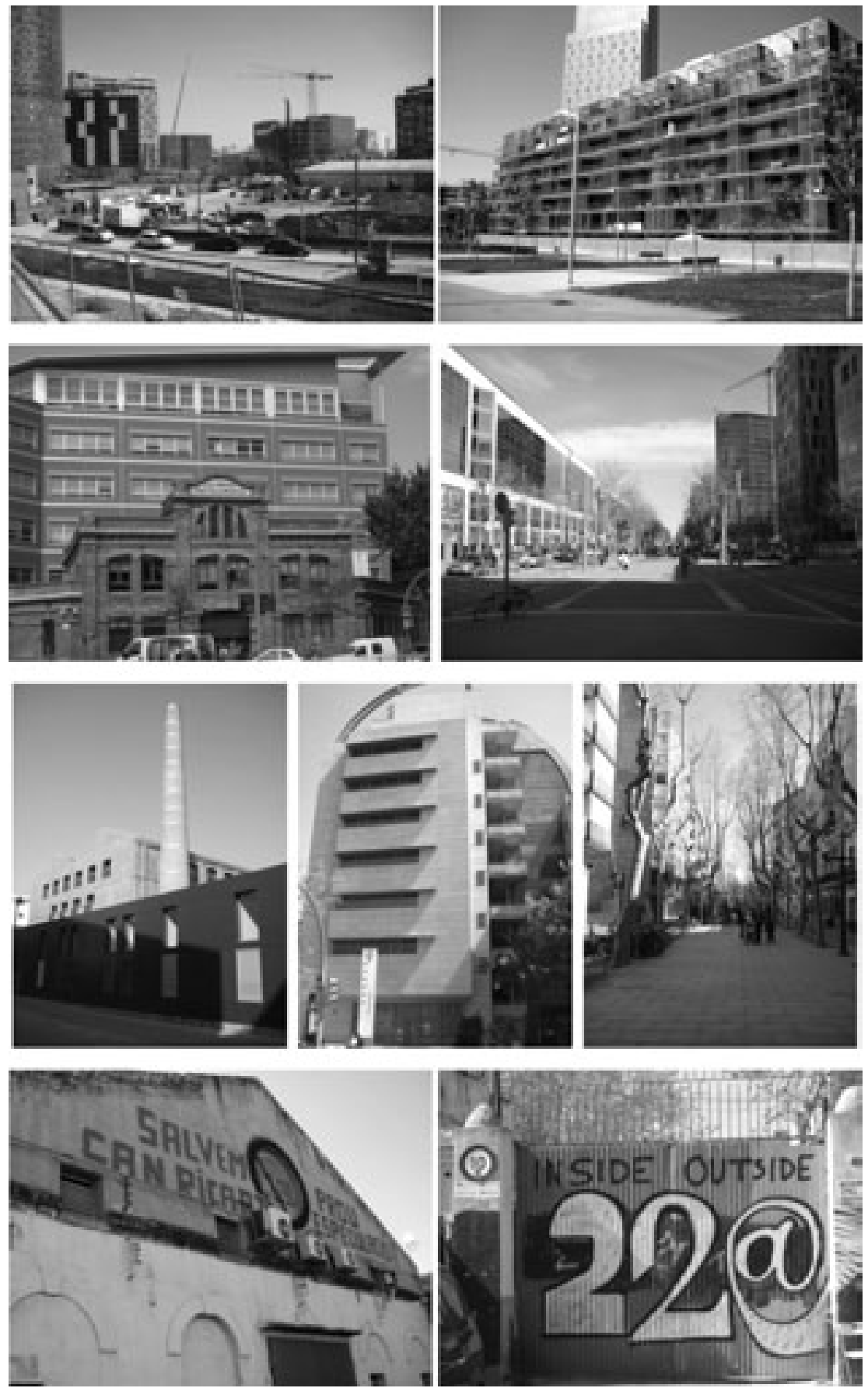

Fig.3 - Bairro de Poblenou / 22@.

Fig.3-Poblenou/22@, Neighbourhood. 
ganha densidade com o aumento da edificabilidade, vê melhorada a qualidade do espaço urbano, já que ganha novas zonas verdes, infra-estruturas e equipamentos, e beneficia de um uso mais eficiente do solo urbano. Todo o processo é delineado pelo Ajuntament de Barcelona, que cria uma empresa de capital 100\% público, mas com gestão privada, a 22@bcn, encarregue de orientar todo o processo de desenvolvimento.

A "filosofia" de desenvolvimento do 22@ pressupõe que na sua base se combinem muito frequentemente acções da administração pública, universidades, centros tecnológicos e de investigação, com as de empresas privadas, formando assim uma "tripla hélice" (Etzkowitz, 2002). Actualmente, em Poblenou estão instaladas áreas científicas e de investigação em crescimento, pertencentes a universidades conceituadas que promovem cursos relacionados com a economia do conhecimento (Jordi Adriá, entrevista Maio 2009).

Como é um sector da cidade ainda em transformação, a diversidade de situações urbanísticas abunda: património industrial abandonado, habitação da classe média, social e de luxo, espaços devolutos, etc. (Queirós, 2009). Mas nem tudo nesta operação de desenvolvimento urbanístico e económico correu bem. A eliminação de uma parte substancial da arquitectura industrial de Poblenou (prevista e executada) é algo que o Ajuntament teve dificuldade em explicar aos habitantes, tendo sido "obrigado" a fazer concessões. Com efeito, as longas e duras negociações entre o Ajuntament e plataformas associativas locais (que trabalharam em concertação com a população local e investigadores universitários), preocupadas com a preservação do património industrial (Salvador Clarós, entrevistas Março e Maio, 20093), resultaram no acréscimo de 68 novos elementos do património industrial de Poblenou ao catálogo do património industrial da cidade.

Hoje o distrito de inovação 22@ ainda convive com o que restou do património industrial do bairro, graças à aprovação do Plano de Protecção do Património Industrial. Este deve-se à referida acção reivindicativa, concertada e persistente, a partir de um movimento social urbano (Associação dos Vizinhos de Poblenou - AVPN; Grupo do Património Industrial do Forum Ribera Bèsos, etc.), que germinou desde o início do projecto (Mercedes Tatjer, entrevista Março $2009^{4}$ ) e cuja milestone decorre com a intervenção associada ao Eix Llacuna.

De acordo com o El Periodico (14/03/2009), o balanço dos resultados do projecto 22@, em finais de 2008, era muito positivo: num universo de 1441 empresas instaladas, 986 (68,4\% das empresas instaladas) relacionavam-se com alguma actividade dos cinco sectores/eixos temáticos. $\mathrm{O}$ emprego criado ascendia a 42 mil trabalhadores e quase $50 \%$ desta nova economia não existia ali

3 Ex-Presidente da Associação de Vizinhos de Poblenou (AVPN), membro da Comissão Obrera Nacional de Catalunya, entrevistado em 2009 e líder do "movimento de contestação 22@" - Património Industrial e Can Ricart. Entrevistado pela autora em 2009.

4 Professora Catedrática da Universidade de Barcelona, membro do Forum Ribera Besòs. Entrevistada pela autora em 2009. 
anteriormente. Em 2010 as informações do site www.22.barcelona.com actualizam aquela informação para Dezembro de 2009: do conjunto de 1502 empresas que então estavam em processo de instalação, ou já instaladas no 22@ desde 2001, mais de 69\% pertencem a um dos cinco sectores estratégicos (media, TIC, TecMed, energia e design) e dos 44.600 novos trabalhadores locais, metade possui formação universitária.

Clua e Albet (2008) alertam para o carácter inovador, complexo e dinâmico do projecto que, até à data, foi suficientemente flexível para a sua sobrevivência. O 22@ foi possibilitado por profissionais e seus conselheiros, que defenderam a necessidade de promover actividades produtivas associadas às TIC. $\mathrm{O}$ incentivo trazido por mais uma grande intervenção urbanística em Barcelona abriu as portas à participação de proprietários e promotores do plano. Os movimentos sociais completam a lista dos actores envolvidos neste projecto. Para Clua e Albet (2008) o processo demonstra simultaneamente a importância da iniciativa pública e a falta de liderança política e de participação popular no processo de planeamento, constituindo estes últimos sérios obstáculos a um adequado desenvolvimento do plano.

Em 2007, por todo o mundo, anunciava-se o fim da prosperidade económica que possibilitou novas áreas de transformação da cidade de Barcelona desde os últimos anos da década de 80 e o início da de 90 (Memòria Estratégica, 2008). No contexto de crise financeira do novo milénio, como se poderá dar continuidade ao movimento de transformação da cidade e, em algumas situações, continuar a obra iniciada com as olimpíadas? O distrito da inovação 22@ dá esperança para responder a esta difícil questão. Os investidores abrandaram, e o crescimento empresarial do 22@ também baixou o seu ritmo mas não estagnou. Possivelmente porque no seu conjunto corresponde a uma boa aposta, territorial e integrada sectorialmente, apesar dos seus problemas de governança. Por isso, talvez seja benéfico que aqui se aplique o que diz Montaner (2003): a cidade constrói-se lentamente, discutindo e melhorando cada projecto e deixando que a cidade evolua e que o debate não termine.

\section{O DEBATE CONTINUA}

O que se vem apresentando com base na experiência de Barcelona diz respeito a certas mudanças ocorridas nos 36 anos após a instalação da democracia, em 1974. Transformações da geografia, economia, cultura e sociedade que, por sua vez, correspondem a processos de modernização desta cidade.

Há ainda a ponderar os limites da fórmula barcelonesa, sobretudo se atendermos, não à Barcelona-cidade, mas à Barcelona-metropolitana. Monclús (2003) adverte para o facto de a dimensão metropolitana ser aquela que é comparável com outras metrópoles europeias, com mais de 4 milhões de habitantes e um território de mais de $3000 \mathrm{~km}^{2}$ (www.cideu.org/).

Na presunção de que o "modelo Barcelona" se formula como uma alterna- 
tiva do Sul da Europa ao sprawl urbano, como se explica então a existência de um intenso processo de suburbanização, acentuada segregação de usos do solo e acrescida dependência do automóvel, fenómenos que ocorrem na área metropolitana nos últimos 20 anos? Apesar de todo o leque de intervenções, desde os anos 1980, para uma "cidade compacta", estaremos perante o paradoxo de uma convergência progressiva com o urban sprawl?

Segundo Capel (2004), o modelo Barcelona foi promovido como o de uma cidade compacta nos anos 1980-90. O autor afirma ainda que a densidade a que o modelo se refere é a que respeita à cidade-município, já que estudos (e estatísticas) demonstram que a aglomeração barcelonesa avançou de forma considerável, correspondendo a uma urbanização dispersa, com tipologias de habitação de baixa densidade, concluindo que a realidade ultrapassou os ideais dos técnicos e políticos responsáveis. Perfilhando esta crítica, Muñoz (2008b) afirma que durante o período em que se exaltou o "modelo Barcelona", o processo de crescimento e expansão da região metropolitana de Barcelona foi tão intenso que deu lugar a um território disperso, completamente distante da imagem de cidade compacta mediterrânea, aquela que possibilitou a atribuição à cidade de Barcelona, de um prémio do Royal Institute of British Architects, em 1999 (McNeill, 2003).

É precisamente sobre o espaço metropolitano que se tem vindo a expandir com base em baixas densidades e em padrões de especialização funcional e de estandardização da paisagem urbana, que trata o artigo de Cebollada e Miralles-Guasch no presente número. Observando a desigual estrutura territorial derivada da utilização intensiva do transporte individual, os autores analisam as diferenças entre o espaço central de Barcelona e a periferia metropolitana. Concluem que as áreas de subúrbio registam uma carência de multifuncionalidade nos seus quotidianos, e que tal é fruto da inaptidão das políticas públicas para inverter estes processos urbanísticos pouco sustentáveis. A mobilidade sustentável é assim um problema por resolver na Barcelona metropolitana, assim como a segregação social decorrente das desigualdades associadas às mobilidades.

Uma crítica em sintonia com a anterior é a que se pode ler no artigo de Díaz-Cortés e Garcia-Ramón (presente volume) na análise dos quotidianos nos usos dos espaços públicos na região metropolitana de Barcelona. Os autores procuram enquadrar o conceito de espaço público de acordo com diversas perspectivas científicas; de entre as diversas visões do que é (ou poderia ser) o espaço público referem o seu importante papel na integração e coesão social, mas alertam para a discriminação e marginalidade que neles pode ocorrer.

É justamente nesta perspectiva que Díaz-Cortés e Garcia-Ramón estudam um espaço público, a Praça de Ca n'Anglada, situada na cidade de Terrassa, na área metropolitana de Barcelona. $\mathrm{O}$ ponto de partida reside no desenho e planificação da praça que corresponde a uma organização "sexista", ligada ao masculino, mas, por oposição, mais utilizada por mulheres, uso derivado do papel 
que a sociedade patriarcal lhes reservou. A abordagem insere-se nos estudos da geografia feminista e cultural que tem dado importantes contributos para a construção das geografias do quotidiano e da memória, e tem um forte cunho empirista e de trabalho de campo. Este estudo constitui um marco inovador da análise dos espaços públicos já que contribui para relançar o tema e estimular uma reflexão sobre a sua reformulação conceptual e a investigação das relações sociais nos quotidianos e o papel que neles assume o espaço público.

Preocupações com as intervenções sociais, o dia-a-dia das famílias e uma sensibilidade especial ao quotidiano das mulheres, revelam-se nos primeiros passos do arquitecto catalão, Ricardo Bofill. É sobre uma polémica obra sua que se desenvolve o artigo de André e Rousselle neste número, partindo do argumento de que este projecto representa uma "estratégia social criativa" no contexto de uma metrópole reconhecida como meio inovador. Conscientes das oportunidades que Barcelona faculta à inovação social, bem como a sua forte imagem cultural, artística e criativa, André e Rousselle confrontam-nos com um caso de estudo em Sant Just Desvern (não muito distante da Ronda de Dalt, na área metropolitana de Barcelona), que se estrutura em torno de um edifício residencial, o Walden-7, um projecto colectivo e idealista inspirado na natureza, simbolizando uma "cidade-jardim no espaço". As autoras associam-no a uma "utopia realizada", um ícone e um monumento ao subúrbio. Um desígnio tão belo que, todavia, conhece contrariedades inimagináveis, sobretudo a partir de 1980. André e Rousselle demonstram que a crise do Walden-7 representa algo mais profundo: a crise de valores sociais. Mas o Walden e os seus residentes ultrapassaram as diversas vicissitudes com muito sentido de solidariedade e forte intervenção pública e hoje é considerado um edifício flagship de Barcelona.

A propósito do tema das identidades sócio-territoriais, Mendizàbal (neste volume), oferece uma visão apaixonada da formação da identidade do bairro de Gràcia, outrora uma vila nas proximidades de Barcelona. Mendizàbal insere esta reflexão no âmbito dos estudos culturais em Geografia e remete para a discussão de importantes e recorrentes conceitos, como identidade, lugar e territorialidade. No contexto de Barcelona, o autor destaca a história e a especificidade da formação deste bairro, como um exemplo da manutenção de uma identidade peculiar dentro de uma grande metrópole. Discorrendo sobre o desenvolvimento da cidade de Barcelona, o seu processo de industrialização e de densificação populacional, Mendizàbal oferece uma lição de geografia, cultural, social e histórica, e demonstra como a tradição operária e catalanista de Gràcia é um exemplo da grande diversidade da composição actual dos habitantes da cidade de Barcelona.

Uma visão crítica ao urbanismo recente de Barcelona manifesta-se no artigo de Gallach e Martì-Costa (no presente número). Os autores apontam, por um lado, para a falta de sensibilidade social da administração pública, e a pouca atenção às necessidades e reivindicações dos residentes e, por outro, para a tendência recorrente de adaptação do território às necessidades do capital, esquecendo o património industrial e identitário da cidade. O planeamento estratégico 
conduzido pelos poderes públicos em Barcelona tem os seus défices, encontrando por isso obstáculos que ecoam através das plataformas de mobilização cidadã. Estamos, assim, perante conflitos sócio-territoriais que Gallach e Martì-Costa muito bem ilustram, através de uma situação conhecida por "Salvem Can Ricart" (uma acção cidadã de defesa do património industrial contra o plano 22@-o recinto Can Ricart, situado em Poblenou era um antigo espaço ocupado por naves industriais). Os autores concluem que "Salvem Can Ricart" demonstra como o futuro da cidade não foi suficientemente debatido e a administração actuou de uma maneira individualizada, o que não é vantajoso para a governança e o futuro da cidade. Atendendo ao conceito apresentado por André e Rousselle neste número, as estratégias apresentadas por Gallach e Martì-Costa constituem igualmente "estratégias sociais criativas" que merecem uma maior atenção por parte da investigação dos geógrafos.

Barcelona associa-se facilmente a noções como criatividade e cultura, constituindo estes traços uma bagagem distintiva e peculiar, fazendo dela uma cidade diferente. Pareja-Eastaway (neste volume), reconhece que muitos já a apelidaram de cidade dos prodígios, cidade das mil faces, cidade dos arquitectos... E que elementos-chave estão a converter Barcelona numa "cidade criativa"? Referindo-se a conceitos relacionados com a cidade criativa, divulgados por académicos conhecidos, como Landry e Florida, Pareja-Eastaway sugere que o conhecimento e o capital humano são também factores essenciais para o desenvolvimento das cidades criativas. Isto significa que o trabalhador criativo, com talento e elevadas qualificações, deve ser uma peça essencial na transformação económica das cidades e, portando, da sua competitividade. Para além da procura de talento associado aos sectores criativos, como forma de aceder à economia do conhecimento, Barcelona apostou na cultura, no entender de Pareja-Eastaway, outro eixo central do crescimento económico e competitividade da cidade. Aliás, a cidade apresenta-se como uma "marca" e um produto cultural. Inúmeros indicadores a demonstrá-lo são identificados pela autora.

Num registo complementar ao de Pareja-Eastaway, Casellas, Jutgla e Pallares-Barbera analisam, neste número, o crescimento económico de Barcelona baseado na produção de uma economia de serviços avançados, na qual as estratégias de marketing de políticas de comunicação e de promoção do turismo jogaram um papel primordial. Os autores enfatizam o impacto económico do turismo e do lazer para a cidade no período de 1990-2010 e concluem com uma reflexão em torno das implicações desfavoráveis para os habitantes de Barcelona e o espaço público. Casellas, Jutgla e Pallares-Barbera, abordam as estratégias que, desde os anos 1980, as cidades em competição usam para "vender um espaço", criar visibilidade exterior e manter uma imagem atractiva. Apontam o turismo como motor da economia local de Barcelona, pelo menos desde os Jogos Olímpicos. No entanto, e em sintonia com a orientação do artigo de Gallach e Martì-Costa deste número, os autores referem a existência de apreciações críticas ao crescimento da indústria turística, apontando os efeitos "colaterais" relacionados com o aumento de valor económico dos solos urbanos e o consequente menor acesso das populações, 
sobretudo nos finais de 2000, o que levou à elaboração de um novo plano estratégico de turismo que introduz a componente da cidadania.

Remetendo para a questão inicial que reproduz a preocupação de Casellas et al., termina esta introdução ao volume XLV (número 90) sabendo que, longe de dar resposta a esta interrogação, o seu objectivo é discutir os processos de transformação de uma metrópole inovadora, cujo modelo de desenvolvimento terá que forçosamente de se reinventar. Até aos nossos dias esta cidade tem demonstrado ser capaz de derrubar todos os obstáculos. O desafio maior será o de suturar e de integrar o território metropolitano: encontrar formas de suceder ao sprawl mediterrâneo e «recombinar a densidade construtiva com a diversidade social e a complexidade urbana» (Muñoz, 2008b: 171).

O último texto deste número, de Horácio Capel, alerta para a "prepotência" das atitudes do Ayuntamiento na construção da cidade e apela para a necessidade de encontrar um outro modelo de urbanismo, assente em novas formas de desenvolvimento económico e de organização social. Do que Barcelona necessita, em sua opinião, é de "novas atitudes políticas e renovados marcos teóricos de actuação territorial”.

Barcelona encerra um mundo de histórias e paradoxos em cenários construídos - pelos seus políticos, profissionais e grupos de cidadãos organizados - com muita criatividade. Juntou-se aqui um extenso conhecimento sobre os processos de (re)construção da cidade e abordou-se a diversidade de escalas sobre as quais podemos "ver" Barcelona. Por isso, é praticamente impossível abarcar todas as mensagens destes artigos numa única leitura, tal a diversidade de horizontes que estes constroem, difíceis de ser absorvidos de um só fôlego. Não é difícil entender porquê. Barcelona é um leque de possibilidades, por isso este número foi intitulado BARCELONA(S). Existe a Barcelona turística, a Barcelona cultural, a Barcelona histórica, a Barcelona monumental, a Barcelona industrial, a Barcelona dos espaços públicos, a Barcelona dos bairros, a Barcelona da cidadania, a Barcelona criativa, a Barcelona-município e a Barcelona-metropolitana, que são todas elas as minhas favoritas Barcelona(s). Esta é uma cidade que se descobre pela primeira vez, depois novamente e de novo se redescobre, vezes sem conta.

Cidade dos projectos ou projectos de cidade? Ambas, porque por um lado, a política de regeneração urbana se tem pautado pela multiplicidade de projectos, pela cultura urbana e participação social. Por outro lado, como dizem Clua e Albet (2008), não pode deixar de estar nos projectos desta cidade o acompanhamento do processo de globalização (Barcelona na economia e sociedade do conhecimento e da informação). É no entanto, chegado o momento de equacionar a proporção exacta entre os benefícios imediatos dos projectos insuficientemente amadurecidos pela sociedade e os ganhos dos projectos de longo horizonte delineados através de um planeamento estratégico urbano impulsionador do consenso social. 


\section{AGRADECIMENTOS}

Agradeço profundamente aos autores dos artigos que muito nos prestigiaram com a sua participação na construção deste número: sem o seu compromisso a revista e os seus leitores perderiam esta oportunidade de reflectir sobre Barcelona; também estou grata aos revisores de todos os textos apresentados neste número: as suas críticas e sugestões permitiram aperfeiçoar a qualidade dos conteúdos.

\section{BIBLIOGRAFIA}

22@barcelona (2005) 22@Barcelona.El districte de la innovació. [brochuras promocionais].

Anuari Territorial de Catalunya (2008) Anuari Territorial de Catalunya 2007. Societat Catalana D'ordenació del Teritori, Barcelona.

Asher F (1995) Metapolis ou l'avenir des villes. Ed. Odile Jacob, Paris.

Barata Salgueiro T, Carreras C (1994) Nota de apresentação. Finisterra - Revista Portuguesa de Geografia, XXIX(57): 1-3.

Borja J (2009) Luces y las sombras del urbanismo de Barcelona. Gestión de la Ciudad. Editorial UOC, Barcelona.

Busquets J (2004) Barcelona. La construcción urbanística de una ciudad compacta. Colección "La estrella polar" 43, Ediciones del Serbal, España.

Capel H (2005) El modelo Barcelona: un examen crítico. Ediciones del Serbal, España.

Casellas A (2006) Las limitaciones del «modelo Barcelona». Una lectura desde Urban Regime Analysis. Documents d'Anàlisi Geogràfica, 48: 61-81.

Clua A, Albet A (2008) 22@bcn Plan: bringing Barcelona forward in the information Era. In Tan Y, Koray V, Scott B (eds.) Knowledge-based urban development: planning and applications in the information era. Hershey: Information Science Reference (IGI Global): 132-147.

Cohen J-L (1998) Learning from Barcelona: vingt ans de projects et leur réception. In Pep Subirós (ed.) Debat de Barcelona (III). Ciutat real, ciutat ideal. Significat i funció a l'espai urbà modern. Centre de Cultura Contemporània de Barcelona: 99-107.

Cruz i Gallach H (2008) Conflictos territorilaes y movilizaciones ciudadanas: algunas reflexiones sobre las formas de gobernanza territorial actuales. Boletín de AGE, 48: 375-387.

Degen M, García M (eds.) (2008) El camino Barcelona: Espacios, culturas y sociedades. In La metaciudad: Barcelona. Transformación de una metrópolis. Anthropos, Barcelona: 9-27.

Etzkowitz H (2002) The triple Helix University - industry - government implications for policy and evaluation. Science Policy Institute. Working paper. Sister: Estocolmo. [www.sister.nu/pdf/ wp_11.pdf]

Garcia-Ramon M-D Albet A (2000) Pré-olympic and Post-Olympic Barcelona, a model for urban regeneration today? Environment and Planning A, 32(8): 1331-1334.

Gaspar J (2008) A cidade no século XXI. Reflexões, desafios, estratégias. Ciclo de conferências na celebração do $10^{\circ}$ aniversário da Expo'98. Parque Expo, Pav. Portugal Lisboa.

McNeill D (2003) Mapping the european urban left: the Barcelona Experience. Antípode, 35(1): 74-94.

Memòria Estratégica (2008) Memoria Estratégica 2008 de L'Associació Pla Estratègic Metropolità de Barcelona. Ajuntament de Barcelona.

Moix L (2002) La ciudad de los arquitectos. $2^{\mathrm{a}}$ ed. Editorial Anagrama, Barcelona.

Monclús F-J (2003) El "Modelo Barcelona”. Una fórmula original? De la "reconstrucción" a los proyectos urbanos estratégicos (1979-2004). Pespectivas urbanas / Urban perspectives, 3: 1-13. (http://www.etsav.upc.edu/urbpersp/num03/index.htm)

Montaner J M (2004) La evolución del modelo Barcelona (1979-2002). In Jordi B, Zaida M (eds.) Urbanismo en el siglo XXI. Una visión crítica. Bilbao, Madrid, Valência, Barcelona. ETSAB, Edicions UCP, 203-222.

Montaner J M, Muxí Z (2002) Los modelos Barcelona: de la acupuntura a la prótesis. Arizona Journal of Hispanic Cultural Studies, 6: 263-268. 
Muñoz F (2008a) Brandcelona: de la reconstrucción urbana al urban sprawl. In Degen M, García M (eds.) La Metaciudad: Barcelona. Transformación de una Metrópolis. Anthropos, Barcelona: 157-178.

Muñoz F (2008b) Urbanalización. Paisages comunes, lugares globales. Editorial Gustavo Gili, Barcelona.

Neves A Oliveira das (1996) Planeamento Estratégico e Ciclo de Vida das Grandes Cidades: os Exemplos de Lisboa e de Barcelona. Celta Editora, Oeiras.

Oliva A (2003) El districte dactivitats 22@bcn. Aula Barcelona. Colecção Model Barcelona. Quaderns de gestió. Universitat de Barcelona, Barcelona.

Pareja-Eastaway M, Garuz J T, Ferrando L G, Pradel i Miquel M, Solsona M S (2008) Main drivers for settlement in the Barcelona Metropolitan region. The managers' view. ACRE Report 6.2, University of Amsterdam, Amsterdam.

Pascual i Esteve J (2007) La estratégia territorial como inicio de la gobernanza democrática. Los planes estratégicos de segunda generación. Colección Documentos de Trabajo, Série Desarrollo Económico. Diputació Barcelona, xarxa de municipis.

PEMB (2009) PMB. Pla Estratègic Metropolità de Barcelona. La transformación del territorio. Desde los proyectos y la acción estratégica. Asociación Plan Estratégico de Barcelona. Barcelona: Ajuntament de Barcelona, 2009.

Queirós M (2010) Territórios emergentes vs. Territórios administrativos: conflito e cooperação para a evolução das culturas de planeamento. VII Congresso da Geografia Portuguesa. FLUC. Coimbra. [Em publicação]

Queirós M (2009) Impressões de uma Geógrafa Portuguesa sobre as Transformações Recentes de Barcelona. Resposta ao desafio de Horacio Capel. Biblio3W. Revista Bibliográfica de Geografía y Ciencias Sociales, XV(850). (Serie Documental de GeoCrítica. Cuadernos Críticos de Geografia Humana). [http://www.ub.es/geocrit/b3w-850.htm]

Queirós M (2002) O ambiente nas políticas públicas em Portugal. Finisterra - Revista Portuguesa de Geografia, XXXVII(73): 33-59.

Sassen S (1991) The global city: New York, London, Tokyo. Princeton University Press, Princeton.

Seixas J (2008) Interpretar a governação urbana contemporânea. Novas perspectivas para a política na cidade. Diez años de cambios en el Mundo, en la Geografía y en las Ciencias Sociales, 1999-2008. Actas del X Coloquio Internacional de Geocrítica, Universidad de Barcelona. [www.ub.es/geocrit/-xcol/52.htm]

Trenc J E, Cebollada A e Miralles-Guasch C (2008) Percepciones de la movilidad y participación ciudadana en la región metropolitana de Barcelona. Ciudad y Território. Estúdios Territoriales, XL(157): 499-510.

Vázquez Montalbán M (1990) Barcelonas. Editorial Empúries, Barcelona. 